\title{
Um poeta sebastianista e sua terra exígua
}

\author{
Paulo Motta Oliveira \\ Universidade Federal de Minas Gerais
}

Del Atlántico mar en la orillas desgreñada y descalza una matrona se sienta al pie de sierra que corona triste pinar. Apoya en las rodillas

los codos y en las manos las mejillas y clava ansiosos ojos de leona en la puesta del sol. El mar entona su trágico cantar de maravillas.

Dice de luengas tierras y de azares mientras ella sus pies en las espumas bañando sueña en el fatal imperio

que se hundió en los tenebrosos mares, y mira cómo entre agoreras brumas se alza Don Sebastián, rey del misterio.

Miguel de Unamuno ${ }^{1}$

Esta é a primeira Nau que parte para as Índias Espirituais, buscando-lhes o Caminho Marítimo através dos nevoeiros da alma, que os desvios, erros, e atrasos da actual civilização lhe ergueram!

Fernando Pessoa ${ }^{2}$

${ }^{1}$ PASCOAES, UNAMUNO, 1986. p. 78.

${ }^{2}$ PESSOA, [s.d.]. p. 78. 


\section{A ponte de tédio}

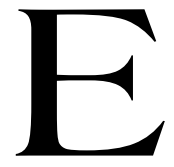

m Lisboa, fevereiro de 1914, um jovem que, como os deuses gostam, morreria cedo, escreveu um poema laconicamente intitulado "7":

Eu não sou eu nem sou o outro,

Sou qualquer coisa de intermédio:

Pilar da ponte de tédio

Que vai de mim para o Outro. ${ }^{3}$

É certo, o tom desistência, de uma vida que sempre está aquém, que é apenas o iniciar de algo que jamais se completa, é uma das marcas seja da poesia finissecular, que perdura no início do século XX, seja particularmente da poética de Mário de Sá-Carneiro. Esse poema ainda poderia ser considerado como uma dos vários representantes do que Bernard Martocq chamou de onda pessimista, que percorre a cultura portuguesa de 1890 a $1910 .{ }^{4}$ Mas, creio, esse quarteto expressa bem mais que uma experiência pessoal ou tão epocalmente limitada. Já Joel Serrão havia apontado para uma possível relação mais próxima entre a experiência pessoal e estética do autor de Princípio e a sociedade em que vivia. Em seu artigo "Perfil esfumaçado de Mário de Sá-Carneiro", após apontar para vários motivos que poderiam ter levado o jovem escritor ao suicídio, considera:

(...) Foram cinco frascos de estriquinina que, em menos de vinte minutos, estancaram, enfim, o fluir do tempo em Mário de Sá-Carneiro. E, em última análise, porquê? Talvez por algo de tudo quanto procuramos dizer, - mas não só por isso. Há mais qualquer coisa, que se entrevê nestas palavras dum suicida de Princípio.

"Afinal, sou simplesmente uma vítima da época, nada mais... O meu espírito é um espírito aventuroso e investigador por excelência. Se eu tivesse nascido no século XV descobriria novos mares, novos continentes... No começo do século XIX teria inventado talvez o caminho de ferro... Há poucos anos, mesmo, ainda teria com o que me

\footnotetext{
${ }^{3}$ SÁ-CARNEIRO,1995. p. 82.

${ }^{4}$ Cf. MARTOQ, 1973.
} 
ocupar: os automóveis, a telegrafia sem fios... Mas agora... agora que me resta? A aviação?... Pf.... essa já nada me interessa depois dos últimos resultados dos Wrightse de Farman... (...) Não há dúvida: a única coisa interessante que existe atualmente na vida é a morte!..."

Não resultará dessa blague juvenil o despontar da consciência de que aquilo que no adolescente se processa é também o reflexo de uma vida e de um mundo muralhados, alimentando-se tão-só do passado, impotentes ante o futuro? Eis uma hipótese de trabalho que seria aliciante desenvolver...5

É essa hipótese que, em parte, iremos aqui seguir, pensando nesse poema de Sá-Carneiro como uma manifestação que pode servir de pista para ligarmos experiências bem diversas que, começando no início do século XIX, chegam ao início do XX. Experiências vividas em uma nação prenhe de passado, carente de futuro.

\section{Um corpo desnudo e a nau da iniciação}

Há cerca de um ano comecei a refletir sobre certos aspectos peculiares das relações entre Portugal e suas colônias, durante o século XIX. Parti, para isso, do já clássico "Psicanálise mítica do destino português" de Eduardo Lourenço. Em um trecho desse ensaio, o crítico afirma: "Quinhentos anos de existência imperial (...) tinham de transformar radicalmente a imagem dos Portugueses não só no espelho do mundo mas no nosso próprio espelho. Pelo império devimos outros". ${ }^{6}$

No mesmo texto, mais à frente, considera:

O Brasil, como a Índia durante uma época, como a África no final, acrescentavam-se, na imaginação do português culto (e por contágio nos outros) ao pequeno país para lhe dar uma dimensão mágica e através dela se constituírem como espaços compensatórios. Potencialmente um "grande país" (...) economizávamos o penoso dever de palpar a nossa pequenez. ${ }^{?}$

${ }^{5}$ SERRÃO, 1983. p. 153.

${ }^{6}$ LOURENÇO, 1978. p. 41.

${ }^{7}$ LOURENÇO, 1978. p. 44. 
Se Índia, Brasil e África serviram para acrescentar à pequena casa lusitana um corpo imaginário com que recobriu a sua própria pequenez, não seria o século XIX justamente um período em que o Brasil não mais existia, e a África ainda não havia sido criada enquanto colônia? Como bem notou Oliveira Marques "Só no século XX (...) é que vantagens de tipo econômico passaram a justificar nitidamente a ocupação portuguesa na África continental". ${ }^{8}$ Não estaria, então, nesse vácuo colonial a raiz do pessimismo que percorre o século, do, como o qualificou ainda Lourenço, "sentimento de fragilidade ôntica relativo à existência pátria"? " Não seria essa a origem da sensação da decadência nacional que, se tem sua expressão mais paradigmática no Causas da decadência de Antero, de fato está presente em todas as obras capitais do século XIX, como apontou João Medina? ${ }^{10}$ Acreditei, e acredito que sim. Pude, partindo dessa hipótese, rastrear algumas das tentativas simbólicas de resolver essa pequenez repentina, gerada pela amputação de parte importante do corpo português. Transitei, assim, pelo que denominei - apropriando-me da famosa expressão de Hobsbawm - de longo século XIX à portuguesa, que abrir-se-ia tardiamente em 1807 - início do corte que prepara a independência brasileira de 1822 - e finda, poderíamos supor, em 1926, quando o pesadelo que fora o sonho republicano é destruído e as sementes do Salazarismo são lançadas. ${ }^{11}$

Boaventura Santos acuradamente notou que Portugal é um país que não pode ser considerado nem como centro, nem como periferia. Foi, durante muito tempo, o centro de periferias e a periferia do centro. ${ }^{12}$ Mas, nesse período intervalar de que aqui tratamos, esse Portugal oitocentista não é o eu nem o outro. Não é mais o eu que foi, perdido o Brasil, não pode ainda ser o outro que surgiria com a concretização do sonho africano. É alguma coisa de intermédio, parado em sua imobilidade como

\footnotetext{
${ }^{8}$ MARQUES, 1986. v.III. p. 157.

9 LOURENÇO, 1978. p. 92.

${ }^{10}$ Cf. MEDINA, 1974. Sobre a imagem da decadência no período ver OLIVEIRA, 2002 (d).

${ }^{11}$ Refleti sobre essas tentativas simbólicas nos ensaios OLIVEIRA, 2002 (b) e OLIVEIRA, 2002 (c).

${ }^{12}$ SANTOS, 1997. p. 58.
} 
o pilar de uma ponte de tédio. Está já, como estará no tempo em que Boaventura Santos escreveu seu artigo, a renegociar a "sua posição no sistema mundial", ${ }^{13}$ perdida que havia sido a sua mais importante colônia. É, especialmente depois do fracasso assinalado pelo Ultimatum, o país perdido do qual o eu de "Inscrição", terrível poema de Pessanha, nos fala.

Eu vi a luz em um país perdido.

A minha alma é lânguida e inerme.

Oh! Quem pudesse deslizar sem ruído!

No chão sumir-se, como faz um verme... ${ }^{14}$

Que saídas para esse país sem caminhos a seguir, para esse ser sem alma? Vários poetas e escritores as propuseram, e por vezes absolutamente antagônicas. O que aqui farei será apenas apontar e refletir sobre algumas, para que possamos melhor entender o papel de Pascoaes nesse contexto. Para tanto, comecemos com Nobre, e com dois de seus poemas, o primeiro publicado em Só e o segundo em Despedidas.

Em certo reino, à esquina do Planeta, Onde nasceram meus Avós, meus Pais, Há quatro lustros, viu a luz um poeta Que melhor fora não a ver jamais.

Mal despontava para a vida inquieta, Logo ao nascer, mataram-lhe os ideais, À falsa fé, numa traição abjecta, Como os bandidos nas estradas reais!

E, embora eu seja descendente, um ramo Dessa árvore de Heróis que, entre perigos E guerras, se esforçaram pelo Ideal:

Nada me importas, País! seja meu Amo O Carlos ou o Zé da T'resa...Amigos, Que desgraça nascer em Portugal!

Coimbra, $1889^{15}$

\footnotetext{
${ }^{13}$ SANTOS, 1997. p. 58.

${ }^{14}$ PESSANHA, 1995. p. 75.

${ }^{15}$ NOBRE, 1979. p. 148.
} 
O que já foste tu [Lisboa], noutras idades

Grande e famosa acima das Nações,

Tu de novo o serás, porque as cidades

Têm varias mortes e ressurreições,

Novas conquistas, outros galeões... ${ }^{16}$

(...)

Velha Lisboa, minha mãe-Madrinha

Tu voltarás a ser o que já foste,

E não, não cuides que é ilusão minha,

Pois nenhuma já tenho a que me encoste!

Não sei quê dentro em mim m'adivinha

Não sei que voz m'o diz de que eu mais goste

E bem no sabes de bem longe: os Poetas

Não se enganam - são bruxos, são Profetas!

(..)

Esperai, esperai, ó Portugueses!

Que ele há-de vir, um dia! Esperai.

Para os mortos os séculos são meses,

Ou menos que isso, nem um dia, um ai.

Tende paciência! finarão revezes;

E até lá, Portugueses! trabalhai.

Que El-Rei-Menino não tarda a surgir,

Que ele há-de vir, há-de vir, há-de-vir! ${ }^{17}$

Estas duas visões quase heteronimicamente distintas, quase pois os dois poemas têm ainda o mesmo estilo, ${ }^{18}$ podem prefigurar o eu cindido do poema de Sá-Carneiro, ou o eu esfacelado de Pessoa. Esses dois poemas de Nobre sintetizam uma tendência que percorre o longo século XIX português - a oscilação freqüente entre momentos de esperança e outros de desalento, oscilação que está inscrita nas principais obras literárias desse período que vai de Garrett a Pessoa. Mas, ao mesmo tempo,

${ }^{16}$ NOBRE, 1945. p. 111.

${ }^{17}$ NOBRE, 1945. p. 115. Uma análise mais detida desse poema pode ser encontrada em OLIVEIRA, 2002(a).

${ }^{18}$ Estamos aqui a pensar no texto de Pessoa sobre os graus do lirismo. Cf. PESSOA, 1986, p. 86-87. 
esses poemas participam de certas tendências que ganharão um contorno mais definido na virada do século: ao lado do desalento, que continuará a existir, surgirá uma esperança que será colocada não em uma nova experiência colonial, mas na criação de um outro tipo de poderio, de caráter cultural ou mesmo religioso.

Essa tendência pode ser detectada nas mudanças que ocorreram, ao longo do final do século XIX e no início do XX, no topos da navegação, que vai incorporar continentes cada vez mais espiritualizados ao destino português.

Já em outro momento mostrei como primeiro Herculano e depois Antero tentaram ver as navegações como característica de um passado que não mais servia para o presente de Portugal. Essa perspectiva será reformulada em História da Civilização Ibérica. No último capítulo desse livro, Oliveira Martins analisará a trajetória da antiga Espanha católica para a nova sociedade que ainda está se formando como uma navegação, que partindo do velho mundo busca por entre nevoeiros o novo porto, ou seja, a futura idéia-síntese que irá congregar a sociedade

Nós acreditamos firme e diremos até piamente (...) na futura organização das nações da Europa; cremos portanto em uma vindoura Espanha mais nobre e mais ilustre ainda do que foi a do século XVI. Acreditamos também que já hoje navegamos na viagem para este porto, embora os nevoeiros conturbem as vistas dos nautas agora que apenas acabamos de largar as costas do velho mundo. ${ }^{19}$

É criado, nesse trecho, um topos que será, a partir de então, recorrente: o destino da península, ou o de Portugal, será visto como a conquista de um poderio equivalente ao antigo, através de novas navegações, não mais terrenas, e sim espirituais. Dessa forma a importância das navegações é recuperada, e elas se transformam em paradigma de um futuro a ser atingido. Mas, notemos, trata-se de navegações espirituais, e não mais terrenas. Não são os continentes descobertos, as antigas colônias perdidas ou as novas colônias a construir o objetivo desse navegar. E nem o poderiam ser. A um Portugal despido de suas peles, apalpando seus ossos em sua pequenez, é proposta uma outra ligação, que o restitua a uma inteireza ainda mais plena e mais prenhe de divino.

${ }^{19}$ MARTINS, 1973. p. 338. 
Será o mesmo Pessanha que em "Inscrição" havia falado em sumirse como um verme, que virá a cristalizar essa mudança em seu poema "San Gabriel”. Nele Portugal é uma nau presa em uma calmaria, da qual só poderá escapar com a ajuda do divino - San Gabriel -, a quem é pedido que de novo abençoe o mar e guie os portugueses à conquista final,

(...) à nebulosa

Que do além vapora, luminosa,

E à noite lactescendo, onde, quietas,

Fulgem as velhas almas namoradas...

Almas tristes, severas, resignadas,

De guerreiros, de santos, de poetas ${ }^{20}$

Apenas chegando a essa nebulosa os portugueses poderão atingir um estado em que o já feito ganhará significado, em que a navegação, iniciada e interrompida no passado, será finalmente completada. Assim, o que em Martins era uma analogia entre a missão passada e o destino futuro, aqui se converte em uma construção mais intrincada: existe essa analogia, mas o passado não possui um significado em si, já que é apenas o início de algo que só em um futuro poderá se consumar. Em um futuro em que Portugal, despido de suas conquistas terrenas, mas tendo com elas aprendido a desejar um destino ascendente, em direção ao divino, poderá ser outro, sendo ainda o mesmo. Estamos no cerne de uma questão que percorre o longo século XIX português, e em especial a sua última parte: como repor a perda, como dar a um povo a quem, julgavam os poetas, faltava alma e não colônias, essa alma perdida? Como transformar a experiência passada de ter tido colônias em uma sabedoria para atingir outro nível de poderio? Foi essa uma das perguntas que, de formas próximas e complementares, Pascoaes e Pessoa responderam.

\section{Um porto sempre por achar}

Uma vez, perguntado se as colônias eram necessárias para o destino português, Fernando Pessoa considerou que elas não eram um estorvo a esse destino, mas não se privou de afirmar: "Para o destino que presumo

${ }^{20}$ PESSANHA, 1973, p. 41. 
que será o de Portugal, as colônias não são precisas". ${ }^{21}$ Pessoa está aqui a apontar que a saída portuguesa não poderia ser a de um imperialismo material. Mais de dez anos antes, Pascoaes, no nº 30 da segunda série de A Águia, havia expressado uma opinião semelhante em seu artigo "O Paroxismo". Esse texto, hoje pouco conhecido, permite que revisitemos o Saudosismo, vendo-o enquanto resposta à carência de sentido desse Portugal ainda sem colônias, e entendamos o papel central que então Pascoaes se outorga nesse processo. Como veremos, as semelhanças entre este autor e Pessoa vão para além do fato de não desejarem um novo imperialismo colonial para o seu país, por não acreditarem ser essa a saída para a pequenez de seu presente.

A segunda série da revista A Águia foi lançada em janeiro de 1912. Nos primeiros três volumes desse periódico, ${ }^{22}$ publicados de janeiro de 1912 a junho de 1913, existiu um grupo de escritores que, aceitando tacitamente a chefia de Pascoaes, defendeu os mesmos ideais, acreditando, entre outros aspectos, que estaria sendo gerada, na poesia portuguesa, uma nova religiosidade ocidental. A partir do quarto volume o autor de Regresso ao Paraíso se verá cada vez mais sozinho na longa polêmica que travará com António Sérgio, ferrenho adversário do Saudosismo, polêmica que tendo se iniciado em outubro de 1913, no no 22 , durará até o no 31 , já no início do sexto volume, de junho de 1914. É quase no final desse período que Pascoaes publicará o texto que aqui nos interessa.

$\mathrm{O} \mathrm{n}^{\circ} 30$ O de A Águia se inicia com o texto "La psychologie des poètes nouveaux et la vie moderne" de Nicolas Beauduin, poeta francês da escola paroxista, de que Philéas Lebesgue, um colaborador freqüente da revista, fazia parte. ${ }^{23}$ Beauduin defende uma poética baseada na ação e na força, valorizando o que considera como as novas conquistas da humanidade. O texto de Pascoaes é uma resposta ao artigo do poeta francês, que lhe é anterior, e assim começa:

${ }^{21}$ PESSOA, [s.d.], p. 164. Essa resposta de Pessoa foi dada ao inquérito sobre o tema "Portugal - Vasto império", realizado por Augusto da Costa no Jornal do Comércio e das Colônias em 1926.

${ }^{22}$ Cada volume era composto por seis números.

${ }^{23}$ Sobre as relações de Lesbegue com a cultura portuguesa ver RIVAS, 1995. 
Em França, Nicolas Beauduin, acompanhado de outros poetas, cria a escola paroxista. Esta palavra deixa já perceber qual é a alma da nova poesia francesa: - a Ação, no significado atual e europeu desta palavra.

(...)

Há um verso de Philéas Lebesgue (...) que sintetiza admiravelmente este novo estado de alma poético francês: "Oú la Force sourit devant la Mort."

A Força, mas a Força conquistadora, eis a sua Musa vigorosa que quer sentir sob os pés o mundo conquistado. A Força que sorri diante da Morte é, sem duvida, a que leva os exércitos à vitória (...). ${ }^{24}$

Logo a seguir Pascoaes considera que também existe "uma Fraqueza no homem digna de ser cantada, - a Fraqueza que nos dá o sentido etéreo das cousas e da Vida", ${ }^{25}$ ao que complementa: "Sim: há duas Realidades. Na imediata, a civilização elabora o seu corpo; na outra o seu espírito". ${ }^{26}$ Pondera então que todos os povos fortes, como os franceses, adoram a primeira, mas que aos portugueses, membros de um pequeno e primitivo país - "Nós somos um povo ainda bárbaro, rural, dominado por vagos sentimentos..." 27 , não é isto o que lhes cabe: "A nossa Realidade não pode ser imediata. Ao ímpeto conquistador dos grandes povos oponhamos sentimentos que o suavizem. Tentemos dar uma alma ao grande corpo.." 28

Em consonância com a visão saudosista, como havia sido expressa nos três primeiros volumes da revista, o atraso do país passa a ser uma vantagem: é ele que permite aos portugueses não pactuarem com o apego à vida material presente nos outros povos europeus e criarem, assim, uma nova vida, que irá dar espírito ao corpo sem alma que as demais nações estão a construir. Este tipo de concepção fica ainda mais evidente quando Pascoaes considera:

Eu compreendo que o Inglês, o Francês, o Alemão regresse, à noite, a casa, orgulhoso do seu país, com os olhos cheios do magnífico

\footnotetext{
${ }^{24}$ PASCOAES, jul. 1914. p. 166.

25 PASCOAES, jul. 1914. p. 166.

${ }^{26}$ PASCOAES, jul. 1914. p. 166.

${ }^{27}$ PASCOAES, jul. 1914. p. 167.

${ }^{28}$ PASCOAES, jul. 1914. p. 166.
} 
espetáculo do seu ruidoso poder dominador. Mas esse Inglês, Francês ou Alemão, ao ver-se a sós na sua alcova, não terá nada que responder a misteriosas perguntas da sua alma? Não a sentirá inquieta e interrogadora no fundo do seu ser?

Tudo isto são perguntas que eu faço, e às quais responde o meu temperamento, talvez a minha própria raça inculta e a minha terra exígua, incapaz de dominar o mundo pela Força.

Para mim, a Vida é a atividade, mas, antes de tudo, atividade de alma, contemplação inquieta, ansiosa de penetrar, com uma prece nos lábios, no Templo escuro do Mistério, onde as estrelas ardem como círios e as montanhas são altares.

A vida é atividade religiosa, sonho de imortalidade. ${ }^{29}$

Se a vida é atividade de alma, os portugueses, incapazes de exercer o poderio, de exaltar a força que gera o progresso, estão mais próximos das verdadeiras fontes, e poderão fornecer as respostas às perguntas que os franceses, ingleses e alemães se fazem quando, em sua alcova, se despem do alarido de seu domínio. Essa nação, que nesse texto de Pascoaes aparece despida de qualquer carne imaginária, enquanto terra exígua, não deve nem pode participar do jogo do progresso material e das novas conquistas. Seu verdadeiro poderio encontra-se em outra parte. Seu império, como também dirá Pessoa, não é deste mundo, mas responderá a necessidades que este mundo possui.

Mas Pascoaes, nesse texto, além de indicar o caminho possível para o país, também refletirá sobre o papel dos poetas nesse processo. Para ele, na origem a vida era verdadeira e os primeiros poetas, como Homero, foram religiosos. Depois a vida se artificializou a tal ponto "que os poetas de hoje, tendo de ser, como sempre, os seus sacerdotes, precisam de ir beber às fontes religiosas, que murmuram no início remoto dos Povos e das Pátrias". ${ }^{30}$ Foi esse o caminho que o próprio Pascoaes seguiu:

A tendência para a dissolução de certas Nacionalidades, é de tal maneira assustadora, que se lhes torna urgente o culto da sua infância. Impõe-se a criação dum novo ciclo mitológico, dando-se às qualidades essenciais duma raça, personalidade própria e divina que a inspire e desperte e lhe insufle um novo alento criador... É o que tentei fazer em Portugal, sintetizado o gênio do Povo na Saudade divinizada...

\footnotetext{
${ }^{29}$ PASCOAES, jul. 1914. p. 167.

${ }^{30}$ PASCOAES, jul. 1914. p. 167.
} 
Precisamos de rejuvenescer, de criar aquele estado de alma em que se desenhou a aparição do Cristo de Ourique... ${ }^{31}$

Logo depois, acrescenta:

Sem poder mítico não há poeta, no sentido primitivo e eterno desta palavra. Por isso, o poeta missionário aparece, em certos momentos da vida dum país; nos seus momentos de fraqueza, em que suas reservas de sonbo e ilusão (a força ascensional, criadora e progressiva) se extinguem, roubando-lhe a carne, o sangue, o colorido vivo ao esqueleto.

Mas o instinto de viver, mais poderoso nos Povos que nos indivíduos, gera, então, novas almas que tenham a faculdade de lhes criar um novo estado de encanto e de ilusão que as dinamize e rejuvenesça.

A Ilusão é a Força das forças, o Sol dos sóis de que falam os hinos védicos. $^{32}$

Assim Pascoaes se considera como o enviado pelas forças vivas da pátria para que ela possa continuar a existir, ou, em seus termos, renascer. Ele é o Messias que pode gerar vida no corpo morto do país, criando uma nova realidade mítico religiosa que deve ser o destino de Portugal: "Se aos outros Povos compete progredir, porque vivem, nós precisamos de reviver primeiramente. Respondamos ao Verbo profano do Progresso com o Verbo divino da Resurreição."33

É impossível ler esse artigo de Pascoaes, que ele por sinal termina dizendo ser "um obscuro poeta lusitano e sebastianista", ${ }^{34}$ sem pensarmos em Pessoa. Está aqui cristalizado muito daquilo que, nas décadas seguintes, estaria disperso em vários dos textos deste poeta que, não o esqueçamos, teve a sua estréia literária em A Águia. Lourenço, por sinal, já havia afirmado:

Não há em toda a nossa literatura um diálogo-combate mais fundo e complexo que o que entrelaça as aventuras poético-espirituais de Pessoa e Pascoaes. Em última análise, a aventura poética de Pessoa é uma tentativa - bem lograda, mas não de todo triunfante - para reestruturar em termos adequados ao seu gênio próprio e a um tempo de

\footnotetext{
${ }^{31}$ PASCOAES, jul. 1914. p. 167.

32 PASCOAES, jul. 1914. p. 167-168.

33 PASCOAES, jul. 1914. p. 168.

${ }^{34}$ PASCOAES, jul. 1914. p. 168.
} 
tecnicidade cosmopolita, o misticismo sem sombra de má consciência poética nem lingüística, do autor inspirado de Regresso ao Paraíso e Marânus. ${ }^{35}$

Também Pessoa falaria da necessidade de criação de um mito nacional, também ele transformaria o seu Mensagem em um poemaprofecia no qual ele seria o terceiro dos avisos do advento do Desejado - momento em que o rei, após ficar imerso "em sonhos que são Deus", 36 retornaria para que ao mundo dividido fosse revelado o Santo Gral. A missão portuguesa, também aqui, é religiosa. O poderio se dá não pela conquista de novas terras, pela construção de novos Brasis em África.

Chegamos ao entrecruzamento em que se irmanam, no início do século XX, esses dois poetas-profetas. Eduardo Lourenço muito bem apontou que foi um erro crítico e uma desatenção cultural considerar o saudosismo de Pascoaes como um passadismo. ${ }^{37}$ Para ele o futuro é a aurora do passado. Eu diria um pouco mais. A saudade pascoalina e também essa outra saudade que percorre o Mensagem de Pessoa e vários dos textos sobre o país que deixou inéditos são respostas para um Portugal que, esperavam, poderia seguir outros destinos imperiais. São uma outra resposta simbólica que tenta cicatrizar a ferida gerada pela perda do Brasil. Infelizmente não foi essa a voz que foi ouvida, mas a de Salazar que deu outras respostas a essa fome. E voltou a recobrir, com peles concretas, com armas e com sangue uma carência que alguns loucos visionários esperavam matar com outro pão. Acredito que relembrar essa faceta de Pascoaes é, nessa nova virada de século em que outros delírios imperiais parecem estar sendo engendrados, uma justa homenagem aos cinqüenta anos da morte desse escritor que, ainda hoje, possui muitos territórios por explorar.

35 LOURENÇO, 1982. p. 107.

${ }^{36}$ PESSOA, 1983. p. 84.

${ }^{37}$ Cf. LOURENÇO, 1978. p. 109. 


\section{Referências Bibliográficas}

LOURENÇO, Eduardo. O labirinto da saudade. Lisboa: Dom Quixote, 1978. MARQUES, Oliveira. História de Portugal. 3. ed. Lisboa: Palas Editores, 1986. MARTINS, Oliveira. História da civilização ibérica.10.ed. Lisboa: Guimarães, 1973.

MARTOCQ, Bernard. Le pessimisme au Portugal (1890-1910). Arquivos do Centro Cultural Português, v. 5, 1973. p.420-458.

MEDINA, João. Eça político. Lisboa: Seara Nova, 1974.

NOBRE, António. Despedidas. 4.ed. Porto: Imprensa Moderna, 1945.

NOBRE, António. Só. 18.ed. Porto: Livraria Tavares Martins, 1979.

OLIVEIRA, Paulo Motta. António Nobre: para além do Só um rei menino de fantástica memória. Voz Lusíada, São Paulo, v. 17, p. 151-166, 2002 (a).

OLIVEIRA, Paulo Motta Mulheres navegantes na apagada e vil tristeza do Portugal oitocentista. In: Marli Fantini Scarpelli; Eduardo de Assis Duarte. Poéticas da diversidade. Belo Horizonte, 2002 (b), p. 259-268.

OLIVEIRA, Paulo Motta Peles americanas em corpo europeu: o Brasil na literatura portuguesa oitocentista. Convergência Lusíada, Rio de Janeiro, v. 19, p. 364-376, 2002 (c).

OLIVEIRA, Paulo Motta. De navegações e naufrágios: imagens de Portugal de Garrett a Pessoa. PEREIRA, Edgard; OLIVEIRA, Paulo Motta; OLIVEIRA, Silvana Maria Pessoa de. Intersecções Ensaios de Literatura Portuguesa. Campinas: Komedi, 2002 (d). p.69-162.

PASCOAES, Teixeira de. O Paroxismo. A Águia, 2. série, Porto, v.5, n.30, p.166168, jun. 1914.

PASCOAES, Teixeira de, UNAMUNO, Miguel de. Epistolário ibérico. Lisboa: Assírio e Alvin, 1986.

PESSANHA, Camilo. Clepsidra e outros poemas. Lisboa: Ática, 1973.

PESSANHA, Camilo. Clepsydra. Lisboa: Relógio D’Água, 1995.

PESSOA, Fernando. Obras em prosa. Rio de Janeiro: Nova Aguilar, 1986.

PESSOA, Fernando. Obra poética. Rio de Janeiro: Nova Aguilar, 1983

PESSOA, Fernando. Portugal, Sebastianismo e Quinto Império. Mem Martins: Europa-América, s.d. 
RIVAS, Pierre. Philéas Lesbegue. Encontro entre literaturas França-BrasilPortugal. São Paulo: Hucitec: 1995. p.73-91.

SÁ-CARNEIRO, Mário. Correspondência literária - A Fernando Pessoa. Obra Completa. Rio de Janeiro: Editora Nova Aguilar, 1995.p. 717-975.

SANTOS, Boaventura de Sousa. Pela mão de Alice. 6.ed. Porto: Afrontamento, 1997.

SERRÃO, Joel. Perfil esfumaçado de Mário de Sá-Carneiro. Temas de Cultura Portuguesa. Lisboa: Livros Horizontes, 1983. p.146-154.

\section{Resumo}

Desde a independência do Brasil até o início do século XX Portugal não teve verdadeiramente colônias. Este artigo pretende analisar algumas das respostas formuladas por escritores para esta situação, e discutir o papel de Teixeira de Pascoaes nesse contexto.

\section{Abstract}

From the independence of Brazil to the beginning of the twentieth century Portugal had to live without a real colony. This essay intends to analyze some answers constructed by Portuguese writers to this situation, and discuss the importance of Teixeira de Pascoaes in this context. 